\title{
Vancomycin bone and tissue concentrations following tibial intraosseous administration - evaluated in a porcine model
}

\author{
Josephine Olsen Kipp ${ }^{1}$, Pelle Hanberg ${ }^{1,2}$, Josefine Slater $^{1}$, Line Møller Nielsen ${ }^{3}$, \\ Stig Storgaard Jakobsen ${ }^{1,4}$, Maiken Stilling ${ }^{1,4}$, and Mats Bue ${ }^{1,4}$ \\ ${ }^{1}$ Orthopaedic Research Unit, Aarhus University Hospital, \\ Palle Juul-Jensens Blvd. 99, 8200 Aarhus N, Denmark \\ ${ }^{2}$ Department of Orthopaedic Surgery, Horsens Regional Hospital, Sundvej 30, 8700 Horsens, Denmark \\ ${ }^{3}$ Department of Clinical Biochemistry, Aarhus University Hospital, \\ Palle Juul-Jensens Blvd. 99, 8200 Aarhus N, Denmark \\ ${ }^{4}$ Department of Orthopaedic Surgery, Aarhus University Hospital, \\ Palle Juul-Jensens Blvd. 99, 8200 Aarhus N, Denmark
}

Correspondence: Josephine Olsen Kipp (josephine.olsen@clin.au.dk)

Received: 18 July 2020 - Revised: 21 January 2021 - Accepted: 3 February 2021 - Published: 12 February 2021

\begin{abstract}
Introduction. Systemic perioperative vancomycin may not provide sufficient prophylactic target-site concentrations in the prevention of prosthetic joint infections. Intraosseous vancomycin potentially provides high target-site concentrations. The objective of the present study was to evaluate the local bone and tissue concentrations following tibial intraosseous vancomycin administration in a porcine model. Methods. Eight pigs received $500 \mathrm{mg}$ diluted vancomycin $(50 \mathrm{mg} / \mathrm{mL})$ through an intraosseous cannula into the proximal tibial cancellous bone. No tourniquet was applied. Microdialysis was applied for sampling of vancomycin concentrations in adjacent tibial cancellous bone, in cortical bone, in the intramedullary canal of the diaphysis, in the synovial fluid of the knee joint, and in the subcutaneous tissue. Plasma samples were obtained as a systemic reference. Samples were collected for $12 \mathrm{~h}$. Results. High vancomycin concentrations were found in the tibial cancellous bone with a mean peak drug concentration of 1236 (range 28-5295) $\mu \mathrm{g} / \mathrm{mL}$, which remained high throughout the sampling period. The mean (standard deviation) peak drug concentration in plasma was 19 (2) $\mu \mathrm{g} / \mathrm{mL}$, which was obtained immediately after administration. Peak drug concentration, time to peak drug concentration, and area under the concentration-time curve were within the same range in the intramedullary canal, the synovial fluid of the knee, and the subcutaneous tissue. Conclusion. Tibial intraosseous administration of vancomycin provided high concentrations in tibial cancellous bone throughout a $12 \mathrm{~h}$ period but with an unpredictable and wide range of peak concentration. The systemic absorption was high and immediate, thus mirroring an intravenous administration. Low mean concentrations were found in all the remaining compartments.
\end{abstract}

Introduction

Prosthetic joint infection (PJI) is a serious and costly complication to joint replacement surgery (Hackett et al., 2015). The economic cost of a PJI is of significant influence for both the patient and the healthcare system, associated with increased morbidity, prolonged hospital admission length, and decreased functional recovery (Hackett et al., 2015; Zmis- towski et al., 2013; Lenguerrand et al., 2017). Perioperative antibiotic prophylaxis is an obligate tool in the prevention of PJI. A successful perioperative antibiotic prophylaxis is dependent on achievement of therapeutic antibiotic target-site concentrations throughout the surgical procedure (Bryson et al., 2016; Mangram et al., 1999). In patients with high risk of developing methicillin-resistant Staphylococcus aureus (MRSA) infections, perioperative vancomycin prophy- 
laxis is recommended (Bratzler and Houck, 2004). However, studies have shown that systemic vancomycin administration may not provide sufficient bone and tissue concentrations in some orthopaedic settings (Bue et al., 2015, 2017; Bryson et al., 2016; Mangram et al., 1999). Local vancomycin application has the potential to bypass these concerns by delivering high target-site concentrations without reaching toxic sideeffects (Sweet et al., 2018; Whiteside, 2016; Young et al., 2014; Wahl et al., 2017). Several local vancomycin applications and carriers are currently available, e.g. powder, calcium sulfate, and irrigation. Particularly in implant surgery, local vancomycin application may be promising to prevent bacterial implant colonization (Whiteside, 2016; Young et al., 2014).

Local vancomycin administration as an addition to systemic antibiotics has been shown to reduce the infection rates in several orthopaedic settings such as tibial fractures and spine surgeries (Craig et al., 2014; Xie et al., 2017). Intraosseous vancomycin administration into the proximal tibia is an easy and feasible local vancomycin application. Intraosseous vancomycin has previously been employed as a perioperative antibiotic prophylaxis in total knee replacement and revision surgery and suggested as enhancing the effectiveness of the perioperative antibiotic prophylaxis (Young et al., 2014; Harper et al., 2020; Young et al., 2018; Chin et al., 2018). These studies assessed vancomycin tissue concentrations by means of tissue specimens, which, however, is limited by its invasiveness, static sampling points, determination of the total, and not free drug concentration. In addition, the concentrations in tissue samples are measured in a homogenate that may include lingered blood and do not appreciate the different tissue compartments. Microdialysis is an alternative method to tissue specimens and is significantly advantaged by allowing for continuous sampling of the active concentrations of vancomycin simultaneously from multiple orthopaedic-relevant sites (Joukhadar and Muller, 2005; Muller, 2002). The objective of this study was to evaluate the local tissue concentrations over a $12 \mathrm{~h}$ period after tibial intraosseous vancomycin administration using microdialysis in a porcine model.

\section{Methods}

The study was conducted at the Institute for Clinical Medicine, Aarhus University Hospital, Aarhus, Denmark. All chemical analyses were performed at the Department of Clinical Biochemistry, Aarhus University Hospital, Aarhus, Denmark. The study involved animals and all the procedures were in accordance with the ethical standards of the institution (the Danish Animal Experiments Inspectorate, license no. 2017/15-0201-01184).

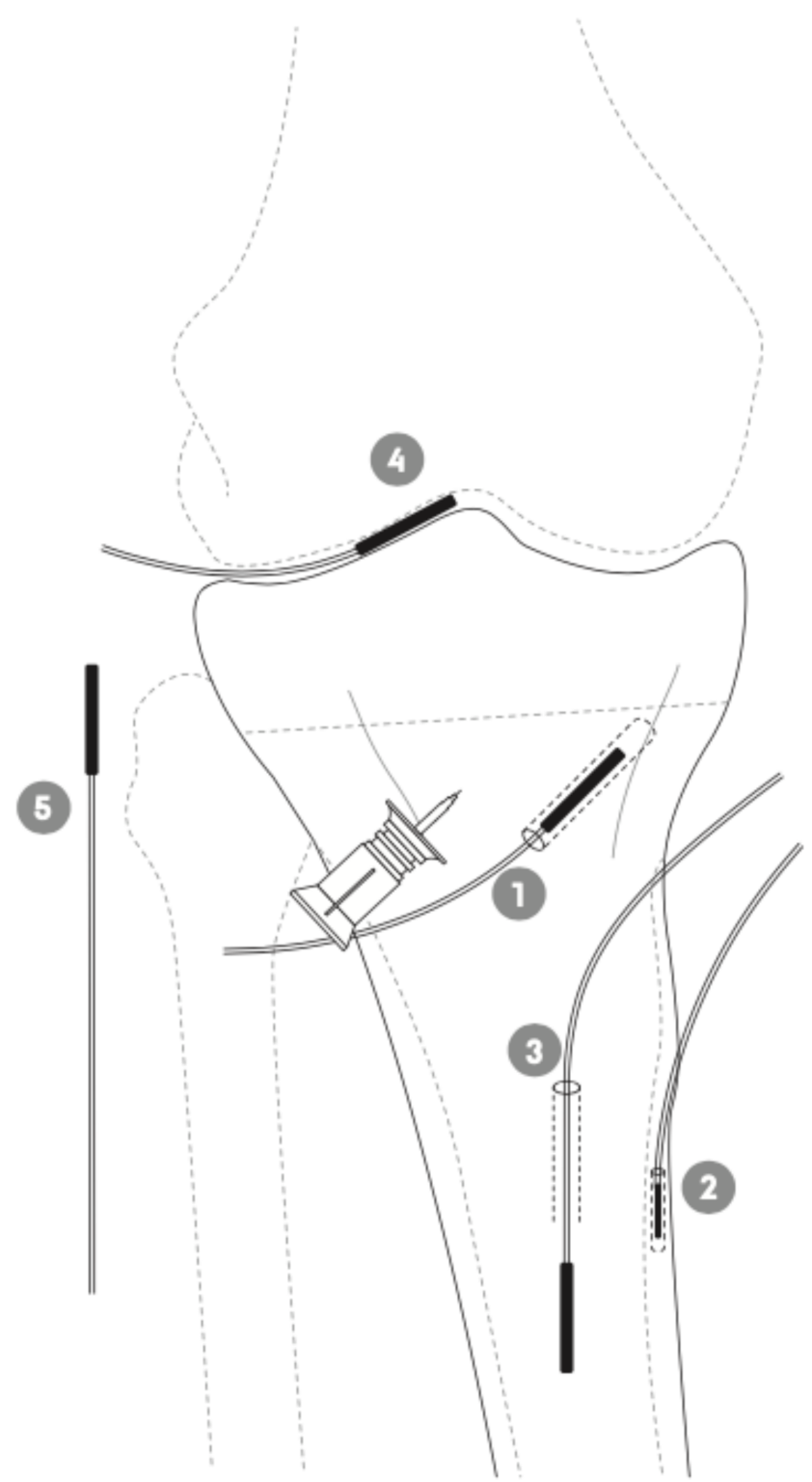

Figure 1. Schematic illustration of the placement of the tibial intraosseous cannula and the microdialysis probes in adjacent cancellous bone (1), cortical bone (2), intramedullary canal (3), synovial fluid of the knee joint (4), and subcutaneous tissue (5) in a porcine model.

\subsection{Animals, anesthesia, and surgical procedures}

Eight female pigs, from the same supplier and raised under the same conditions, were included in the study (Danish Landrace Breed, age 5 months, weight $78-82 \mathrm{~kg}$ ). The pigs were kept under general anesthesia with a continuous infusion of propofol $(450-650 \mathrm{mg} / \mathrm{h})$ and fentanyl $(0.5-0.7 \mathrm{mg} / \mathrm{h})$ throughout the entire study period. The arterial $\mathrm{pH}$ and body temperature were monitored and kept in the ranges of 7.377.52 and $36.4-40.0^{\circ} \mathrm{C}$, respectively. After the study, the pigs were euthanized using pentobarbital. 
An intraosseous cannula $(15 \mathrm{~mm})$ was inserted into the medial tibial condyle approximately $10 \mathrm{~mm}$ distal to the epiphyseal line; see Fig. 1. Three tibial microdialysis probes were placed in drill holes, one in the adjacent cancellous bone parallel to and at a mean distance of 9 (range 7-10) $\mathrm{mm}$ from the intraosseous cannula tip (drill depth $35 \pm 1 \mathrm{~mm}$ ), one in the cortical bone at the anterior-medial margin of the tibial diaphysis (drill depth $14 \pm 0.5 \mathrm{~mm}$ ), and one within the intramedullary canal of the tibial diaphysis. All drill holes were made with a $2 \mathrm{~mm}$ drill, which was paused every few seconds to prevent overheating of the bone tissue. Subsequently, a probe was placed in the synovial fluid of the knee joint using a splittable introducer. Finally, a subcutaneous tissue probe was placed lateral to the knee joint. No tourniquet was applied. Correct positions of all the probes and the distance between the intraosseous cannula and the adjacent cancellous bone microdialysis catheter were verified by fluoroscopy. Placement and length of all drill holes were visualized for control by a postmortem computed tomography (CT) scan, which confirmed that all drill holes were placed as intended.

\subsection{Microdialysis}

Microdialysis is a membrane-bearing probe technique allowing for dynamic sampling of molecules from the interstitial space from the tissue of interest (Joukhadar and Muller, 2005; Muller, 2002; Tottrup et al., 2019; Hanberg et al., 2019). Due to continuous perfusion of the microdialysis system, a complete equilibrium across the semipermeable membrane will never occur. The concentration in the dialysate will therefore only represent a fraction of the absolute tissue concentration, which is expressed as the relative recovery. Thus, relative recovery must be determined to assess the absolute tissue concentrations. In the present study, all microdialysis probes were individually calibrated in the beginning of the study using the retrodialysis by drug method (Scheller and Kolb, 1991).

In the present study we used CMA 107 precision pumps ( $\mu$-Dialysis AB, Stockholm, Sweden) producing a flow rate of $1 \mu \mathrm{L} / \mathrm{min}$ and CMA 70 probes (membrane lengths 10 and $20 \mathrm{~mm}$, molecular cutoff $20 \mathrm{kDa}$ ).

\subsection{Sampling procedures}

Immediately after placement, the probes were perfused with isotonic saline containing $2.5 \mu \mathrm{g} / \mathrm{mL}$ vancomycin, followed by a $30 \mathrm{~min}$ tissue equilibration period. Afterwards, all probes were individually calibrated by the retrodialysis method by collecting a $60 \mathrm{~min}$ sample. The perfusate was then changed to isotonic saline followed by a $180 \mathrm{~min}$ washout period in order to prevent calibration leftovers of vancomycin. A vancomycin $(500 \mathrm{mg})$ and saline $(10 \mathrm{~mL})$ dilution at $50 \mathrm{mg} / \mathrm{mL}$ was injected over $30 \mathrm{~s}$ at time zero through the intraosseous cannula and flushed with $3 \mathrm{~mL}$ saline. The first three dialysates were collected at times 40 , 80 , and $120 \mathrm{~min}$. Thereafter, dialysates were collected at $60 \mathrm{~min}$ intervals from times 120 to $720 \mathrm{~min}$, giving a total of 13 samples from each compartment over $12 \mathrm{~h}$. Blood samples were drawn from a central venous catheter at the midpoint of the microdialysis sample intervals. The dialysates were instantly stored at $-80^{\circ} \mathrm{C}$ until analysis. Blood samples were stored at $5{ }^{\circ} \mathrm{C}$ for a maximum of $4 \mathrm{~h}$ before being centrifuged at $3000 \mathrm{rpm}$ for $10 \mathrm{~min}$. The obtained plasma aliquots were then stored at $-80^{\circ} \mathrm{C}$ until analysis.

\subsection{Vancomycin quantification}

The free concentration of vancomycin in plasma was quantified with a homogeneous enzyme immunoassay technique using the Siemens Chemistry XPT platform (Advia Chemistry, Erlangen, Germany). Intra-run (total) imprecisions for the assay were $\pm 1.2 \mu \mathrm{g} / \mathrm{mL}$ ( 2 standard deviations $-\mathrm{SD}$ ) at 6.6 and $\pm 3.7 \mu \mathrm{g} / \mathrm{mL}$ ( $2 \mathrm{SD}$ ) at $29.1 \mu \mathrm{g} / \mathrm{mL}$. The vancomycin concentrations in the dialysates were quantified using ultrahigh performance liquid chromatography (Bue et al., 2015). The intra-run (total) imprecisions (percent coefficient of variation $-\% \mathrm{CV}$ ) were evaluated at three different vancomycin concentrations: $3.7 \%(5.7 \%)$ at $0.7 \mathrm{~g} / \mathrm{mL}, 3.0 \%(3.5 \%)$ at $3.7 \mathrm{~g} / \mathrm{mL}$, and $0.9 \%(2.2 \%)$ at $5.2 \mathrm{~g} / \mathrm{mL}$. The quantification limit was defined as the lowest concentration with intra-run $\mathrm{CV}<20 \%$ and was found to be $0.05 \mu \mathrm{g} / \mathrm{mL}$.

\subsection{Statistics}

Standard pharmacokinetic parameters were determined separately for each compartment in each pig by noncompartmental analysis using Stata (v. 14.1, StataCorp LLC, College Station, TX, USA). The area under the concentration-time curve $\left(\mathrm{AUC}_{0-\text { last }}\right)$ was calculated using the trapezoidal rule. The maxima of all the recorded concentrations were defined as peak drug concentration $\left(C_{\max }\right)$ and enabled a calculation of the time to $C_{\max }\left(T_{\max }\right)$. Halflife $\left(T_{1 / 2}\right)$ was determined for all compartments except for tibial cortical bone and calculated as $\ln (2) / \lambda_{\text {eq }}$, where $\lambda_{\text {eq }}$ is the terminal elimination rate constant estimated by linear regression of the log concentration on time. For $\mathrm{AUC}_{0-\text { last }}$ and $C_{\max }$, a mixed model for repeated measurements was applied, taking the variance between pigs into account. The model assumptions were tested by visual diagnosis of residuals, fitted values, and estimates of random effects. A correction for degrees of freedom due to small sample size was handled using the Kenward-Roger approximation method. The $t$ test was used to determine relevant pairwise comparisons. A $p$ value $<0.05$ was considered to be significant. A Spearman test was used to test the correlation between the distance of the intraosseous cannula and the adjacent cancellous bone drill hole with the peak drug concentration. Statistical analyses were also performed using Stata. The mean values with the following $\mathrm{SD}$ of $\mathrm{AUC}_{0-\text { last }}, C_{\max }, T_{\max }$, and $T_{1 / 2}$ are pre- 
sented in Table 1. The dialysate concentrations were ascribed to the midpoint of the sampling intervals. Values below the quantification limit were set to zero. The washout concentrations were low and therefore not included in the analysis model.

\section{Results}

All eight pigs completed the study and all the probes were functioning. Mean (SD) relative recovery was $41.5 \%$ $(10.7 \%)$ in the tibial cancellous bone, $45.5 \%(7.1 \%)$ in the tibial cortical bone, $44.4 \%(8.2 \%)$ in the intramedullary canal, $55.3 \%$ (19.4\%) in the synovial fluid of the knee joint, and $46.7 \%(11.1 \%)$ in subcutaneous tissue.

All the pharmacokinetic parameters are displayed in Table 1. Individual concentration-time profiles of vancomycin in the tibial cancellous bone are displayed in Fig. 2. The mean concentration-time profiles for the remaining compartments are presented in Fig. 3. The mean vancomycin $C_{\max }$ (SD) for tibial cancellous bone was $1236(1883) \mu \mathrm{g} / \mathrm{mL}$ with a range of $28-5295 \mu \mathrm{g} / \mathrm{mL}$. There was no statistically significant correlation between the distance from the intraosseous cannula to the adjacent cancellous bone drill hole and the $C_{\max }$ (Fig. 4). Two pigs presented approximately 10-fold higher tibial cancellous bone concentrations and one pig approximately 10-fold lower in comparison to the remaining pigs (Fig. 2). After $11.5 \mathrm{~h}$ (690 min), the mean (SD) vancomycin concentration was 278 (range $3-1363$ ) $\mu \mathrm{g} / \mathrm{mL}$ in tibial cancellous bone. For the remaining compartments, the highest $C_{\max }$ (SD) of 19 (2) $\mu \mathrm{g} / \mathrm{mL}$ was found in plasma, which was achieved immediately after administration, while the lowest $C_{\max }$ (SD) of 1 (1) $\mu \mathrm{g} / \mathrm{mL}$ was found in tibial cortical bone. For the intramedullary canal, the synovial fluid of the knee joint, and subcutaneous tissue, comparable AUC and $C_{\max }$ were found.

\section{Discussion}

We performed a $12 \mathrm{~h}$ dynamic evaluation of the local bone and tissue concentrations following intraosseous administration of $500 \mathrm{mg}$ diluted vancomycin into the proximal tibial cancellous bone. The main finding was a high mean peak drug concentration of $1236 \mu \mathrm{g} / \mathrm{mL}$ in the adjacent tibial cancellous bone with an unpredictable and large inter-pig variation. Two pigs presented approximately 10 -fold higher tibial cancellous bone concentrations and one pig approximately 10 -fold lower in comparison to the rest. The end mean (SD) concentration in adjacent cancellous bone was $278(469) \mu \mathrm{g} / \mathrm{mL}$.

The large inter-pig difference in vancomycin concentrations in cancellous bone cannot readily be explained. We only sampled from one drill hole in the cancellous bone adjacent to the intraosseous cannula. The postmortem CT scan verified similar distance and no direct bone communication between the intraosseous cannulas and cancellous drill holes. Although microdialysis is a dynamic sampling technique displaying low intra-pig cancellous bone variation, the sampling site is static, which prohibits the possibility of encompassing the complete variation in the local dilution potential in the entire proximal tibial cancellous bone. Furthermore, the local dilution potential may be influenced by individual bone factors such as density and architecture. Our findings may therefore, to some extent, illustrate the challenge of controlling the local concentration of vancomycin, when vancomycin is administered locally in diluted form, rather than inadequacy of the applied method. However, this needs further investigation.

Systemic perioperative vancomycin may not provide sufficient prophylactic target-site concentrations exceeding relevant minimal inhibitory concentrations (MICs) in the prevention of PJI (Bue et al., 2015). In total knee replacement patients, sufficient vancomycin tissue concentrations were reached with a substantial delay or not at all, particularly in cortical bone when applying a standard prophylactic dosage of $1 \mathrm{~g}$ of vancomycin (Bue et al., 2017). Intraosseous vancomycin administration has the potential to overcome this concern by providing high target-site concentrations. In order to achieve adequate perioperative antibiotic prophylaxis, it is recommended that target-site concentration exceed the MIC values of relevant bacteria throughout the surgical procedure (Bryson et al., 2016; Mangram et al., 1999). Commonly encountered bacteria in orthopaedic infections exhibit planktonic MIC in the range of $0.5-4 \mu \mathrm{g} / \mathrm{mL}$ for vancomycin (Rybak, 2006; EUCAST, 2019). Using a high target limit of $4 \mu \mathrm{g} / \mathrm{mL}$ for all investigated extravascular compartments, sufficient mean vancomycin concentrations were only found in tibial cancellous bone for all pigs throughout the $12 \mathrm{~h} \mathrm{sam}$ pling interval, whereas the remaining compartments did not reach the target limit in all subjects. Our findings suggest that tibial intraosseous administration of $500 \mathrm{mg}$ diluted vancomycin, without the use of a tourniquet, provides high but unpredictable tissue concentrations in the adjacent proximal tibial cancellous bone. Whether our findings are applicable to other anatomical bone locations needs further investigation.

In plasma, the mean (SD) peak vancomycin concentration of 19 (2) $\mu \mathrm{g} / \mathrm{mL}$ was achieved immediately after administration, demonstrating a prompt absorption to the systemic circulation. These findings are consistent with the general indication for the use of tibial intraosseous administration. Interestingly, the plasma variations of vancomycin were much lower than those found in tibial cancellous bone. This may indicate a uniform systemic distribution, whereas the local dilution potential and thus maintenance of a high local vancomycin concentration in the proximity of the intraosseous cannula varied to a great extent. The local dilution potential is dependent on and determined by various factors, e.g. the surface area of the cancellous bone and the volume and composition of the encircling bone marrow. As demonstrated by other antibiotic microdialysis studies, bone tissue may 
Table 1. Key pharmacokinetic parameters given as a mean (SD) for tibial cancellous bone, tibial cortical bone, the intramedullary canal in the tibia, the synovial fluid of the knee joint, subcutaneous tissue, and plasma.

\begin{tabular}{|c|c|c|c|c|}
\hline Tissue & $\mathrm{AUC}_{- \text {last }}(\mathrm{min} \mu \mathrm{g} / \mathrm{mL})$ & $C_{\max }(\mu \mathrm{g} / \mathrm{mL})$ & $T_{\max }(\min )$ & $T_{1 / 2}(\min )$ \\
\hline Tibial cancellous bone & 374637 (513 172) & $1236(1883)$ & $111(94)$ & $279(188)$ \\
\hline Tibial cortical bone & $326(331)$ & $1(1)$ & $405(278)$ & \\
\hline Intramedullary canal in the tibia & $1980(908)^{\mathrm{a}}$ & $8.2(4)^{\mathrm{a}}$ & $65(26)$ & $339(332)$ \\
\hline Synovial fluid of the knee joint & $1565(758)^{\mathrm{a}}$ & $6.5(4)^{\mathrm{a}}$ & $45(21)$ & $217(140)$ \\
\hline Subcutaneous tissue & $1881(691)^{\mathrm{a}}$ & $7.7(3)^{\mathrm{a}}$ & $70(19)$ & $361(269)$ \\
\hline Plasma & $3,673(611)$ & $19(2)$ & $20(19)$ & $254(128)$ \\
\hline
\end{tabular}

$\mathrm{AUC}_{0-\text { last }}$ : area under the concentration-time curve from 0 to the last measured value; $C_{\max }$ : peak drug concentration; $T_{\max }$ : time to $C_{\max }$; $T_{1 / 2}$ : half-life at phase. ${ }^{a} p>0.35$ for all pairwise comparisons of means between the intramedullary canal, synovial fluid of the knee joint, and subcutaneous tissue.
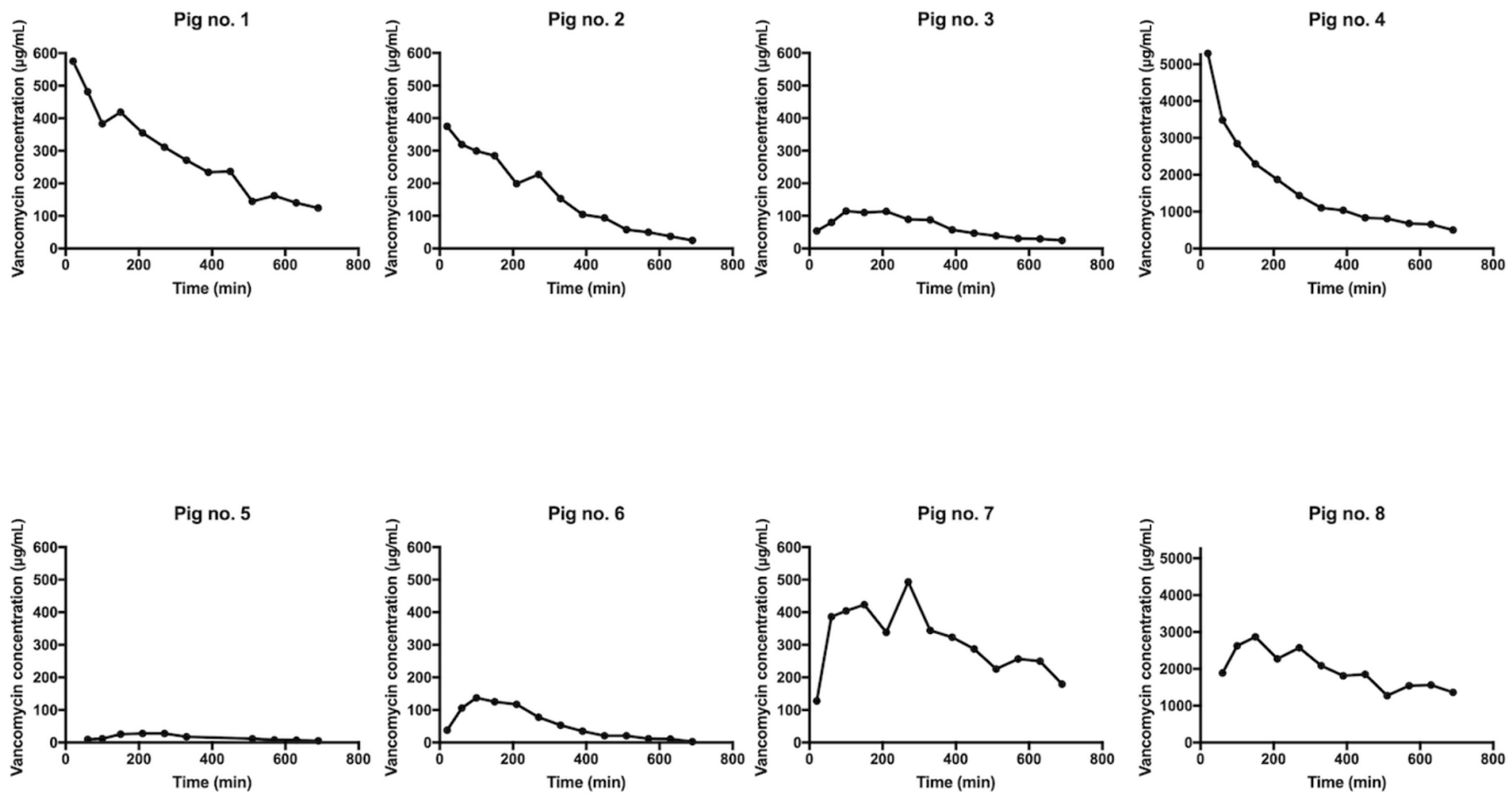

Figure 2. Individual concentration-time profiles for tibial cancellous bone adjacent to the intraosseous cannula in pig nos. 1-8. The $y$ axis for pig nos. 4 and 8 is 10-fold higher than the rest.

present as a difficult diffusion medium for antibiotics, especially if the bone is infected or inflamed (Jensen et al., 2017; Bue et al., 2019; Thomassen et al., 2020). This may be due to the compact tissue structure generating a higher fluid pressure, indirectly suggesting that most of the concentrations achieved in all the other extravascular tissues in the present study are delivered from the systemic circulation.

The goal of local vancomycin administration is to provide high target-site concentrations without reaching toxic systemic levels. To achieve this, the systemic absorption must be low. The present study could not confirm such a theoretical advantage of tibial intraosseous vancomycin administration. The mean peak drug concentrations in subcutaneous tissue and plasma were 2-3-fold lower in the present study than in a similar porcine study with intravenous administration of
$1000 \mathrm{mg}$ vancomycin (Bue et al., 2015). This raises an interesting question of whether an equivalent intraosseous dose of $1000 \mathrm{mg}$ vancomycin would mirror the tissue concentrations from the intravenous setup but with higher tibial cancellous bone concentrations.

Vancomycin pharmacokinetics after intraosseous vancomycin administration have previously been examined in three clinical $(250$ and $500 \mathrm{mg}$; injection concentrations of $1.25,2.5$, and $3.33 \mathrm{mg} / \mathrm{mL}$ ) and three experimental studies on rats (approximately $12.5 \mathrm{mg}$; injection concentration of $250 \mathrm{mg} / \mathrm{mL}$ ), horses $(300 \mathrm{mg}$; injection concentration of $5 \mathrm{mg} / \mathrm{mL}$ ), and micropigs (approximately $350 \mathrm{mg}$; injection concentration of $17.5 \mathrm{mg} / \mathrm{mL}$ ), respectively (Young et al., 2014; Loc-Carrillo et al., 2016; Rubio-Martinez et al., 2006; Chastagner et al., 2001; Chin et al., 2018; Young et al., 


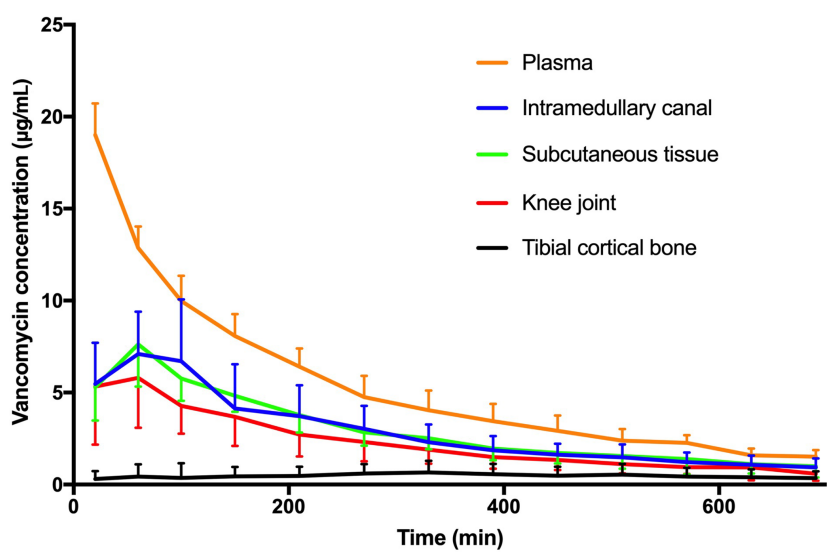

Figure 3. Mean concentration-time profile for plasma, intramedullary canal, subcutaneous tissue, synovial fluid of the knee joint, and tibial cortical bone. Bars represent standard deviation.

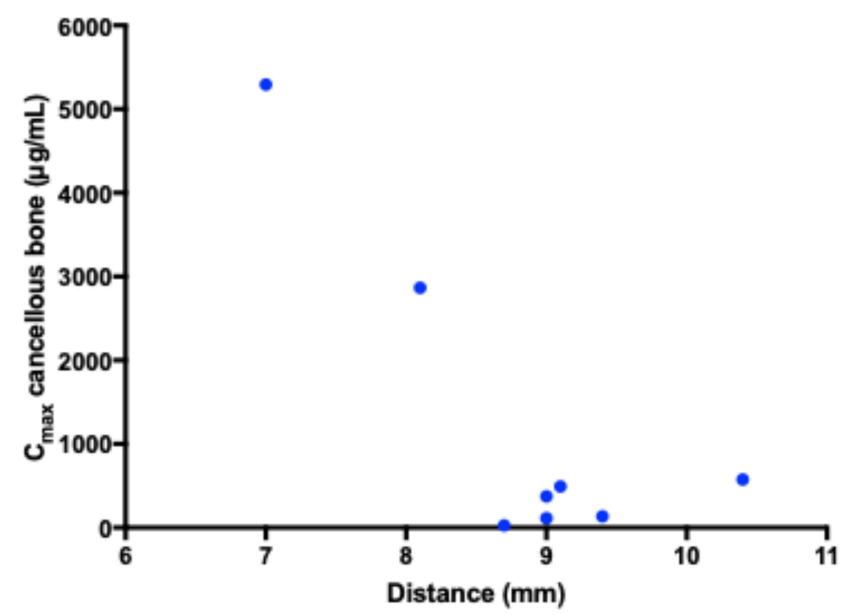

Figure 4. Correlation between the distance from the intraosseous cannula and the adjacent cancellous bone drill hole with the peak drug concentration. No correlation was found.

2018). Across these clinical and experimental studies, the mean peak drug plasma concentrations are reported in the range of 1.8 to $11 \mu \mathrm{g} / \mathrm{mL}$, which is considerably lower than found in the present study (Young et al., 2014; Chin et al., 2018; Loc-Carrillo et al., 2016; Rubio-Martinez et al., 2006; Chastagner et al., 2001). Three of the studies (two clinical and one experimental) applied a proximal tourniquet before intraosseous administration, resulting in systemic vancomycin plasma levels of $0.0-2.7 \mu \mathrm{g} / \mathrm{mL}$ during inflation and a 4-10-fold increase after deflation (range: $1.8-6.0 \mu \mathrm{g} / \mathrm{mL}$ ) (Young et al., 2014; Chin et al., 2018; Rubio-Martinez et al., 2006). The differences in plasma levels between these studies and the present study may be explained by the use of a tourniquet, different vancomycin doses, interspecies differences, and different sampling methods. Bone concentrations of vancomycin were examined in four of the studies (three clinical and one experimental) by means of tissue specimens
(Loc-Carrillo et al., 2016; Young et al., 2014; Chin et al., 2018; Young et al., 2018). These studies demonstrate parallel variations in vancomycin bone concentrations with the present study. Any further comparisons are, however, complicated for several reasons; e.g. no application of tourniquet or major surgery was performed in the present study, and different sampling techniques, sites, and species were investigated. This study is the first to perform a dynamic assessment of vancomycin concentrations in cancellous bone adjacent to the intraosseous cannula and simultaneously from multiple orthopaedically relevant compartments over $12 \mathrm{~h}$.

This study has a number of limitations. First, the variation in cancellous bone concentrations may imply that the sample size was too small. However, the limited systemic and intrapig variation may indicate otherwise. Second, although pigs resemble humans in terms of physiology, anatomy, and the composition of bone, the interspecies and bone age differences have an effect on the translation potential of the presented results (Swindle et al., 2012; Aerssens et al., 1998). The weight of the pigs was chosen in order to resemble average human adult body weight. However, a young female pig (aged 5 months) weighing approximately $80 \mathrm{~kg}$ is still juvenile. Third, although validated for each matrix, vancomycin dialysate and plasma concentrations were quantified on two different assays, which may limit generalizability to some extent. Finally, microdialysis remains a sampling technique and is therefore exposed to limitations associated with the calibration procedures and chemical assay (Scheller and Kolb, 1991).

In conclusion, tibial intraosseous administration of $500 \mathrm{mg}$ diluted vancomycin, without the use of a tourniquet, was found to provide high mean concentrations, well above the MIC target of $4 \mu \mathrm{g} / \mathrm{mL}$, suitable for antibiotic prophylaxis, in all subjects, in adjacent proximal tibial cancellous bone throughout a $12 \mathrm{~h}$ sampling period. However, the concentrations in cancellous bone exhibited a large and unpredictable inter-pig variation. The systemic absorption was prompt and high, mirroring an intravenous administration, while none of the remaining extravascular compartments were able to reach a concentration of $4 \mu \mathrm{g} / \mathrm{mL}$ in all subjects.

Ethical statement. The study involved animals, and all the procedures were in accordance with the Interdisciplinary Principles and Guidelines for the Use of Animals in Research, Testing, and Education by the New York Academy of Sciences Ad Hoc Animal Research Committee and were approved the Danish Animal Experiments Inspectorate, license no. 2017/15-0201-01184.

Data availability. The data that support the findings of this study are available from the corresponding author upon reasonable request. 
Author contributions. JOK, $\mathrm{PH}, \mathrm{JS}, \mathrm{SSJ}, \mathrm{MS}$, and MB initiated and designed the study. JOK, PH, JS, and MB performed the surgery and collected the data. LMN performed the chemical analysis. Statistical analysis and interpretation of the data was done by JOK, PH, JS, SSJ, MS, and MB. JOK drafted the manuscript. All the authors read, revised, and approved the manuscript.

Competing interests. The authors declare that they have no conflict of interest.

Financial support. This research has been supported by the Læge Sophus Carl Emil Friis og hustru Olga Doris Friis' Legat.

Review statement. This paper was edited by Alex McLaren and reviewed by three anonymous referees.

\section{References}

Aerssens, J., Boonen, S., Lowet, G., and Dequeker, J.: Interspecies differences in bone composition, density, and quality: potential implications for in vivo bone research, Endocrinology, 139, 663670, https://doi.org/10.1210/endo.139.2.5751, 1998.

Bratzler, D. W. and Houck, P. M.: Antimicrobial prophylaxis for surgery: an advisory statement from the National Surgical Infection Prevention Project, Clin. Infect. Dis., 38, 1706-1715, https://doi.org/10.1086/421095, 2004.

Bryson, D. J., Morris, D. L., Shivji, F. S., Rollins, K. R., Snape, S., and Ollivere, B. J.: Antibiotic prophylaxis in orthopaedic surgery: difficult decisions in an era of evolving antibiotic resistance, Bone Joint J., 98-B, 1014-1019, https://doi.org/10.1302/0301-620X.98B8.37359, 2016.

Bue, M., Birke-Sorensen, H., Thillemann, T. M., Hardlei, T. F., Soballe, K., and Tottrup, M.: Single-dose pharmacokinetics of vancomycin in porcine cancellous and cortical bone determined by microdialysis, Int. J. Antimicrob. Ag., 46, 434-438, https://doi.org/10.1016/j.ijantimicag.2015.06.014, 2015.

Bue, M., Tottrup, M., Hanberg, P., Langhoff, O., Birke-Sorensen, H., Thillemann, T. M., Andersson, T. L., and Soballe, K.: Bone and subcutaneous adipose tissue pharmacokinetics of vancomycin in total knee replacement patients, Acta Orthop., 89, 95-100, https://doi.org/10.1080/17453674.2017.1373497, 2017.

Bue, M., Thomassen, M. B., Larsen, O. H., Jorgensen, A. R., Stilling, M., Soballe, K., and Hanberg, P.: Local Vancomycin Concentrations after Intra-articular Injection into the Knee Joint: An Experimental Porcine Study, The Journal of Knee Surgery, in press, https://doi.org/10.1055/s-0039-3402078, 2019.

Chastagner, P., Lozniewski, A., Lascombes, P., Barberi-Heyob, M., Merthes, P. M., and Merlin, J. L.: Pharmacokinetic longitudinal studies of antibiotics administered via a permanent intraosseous device in micropigs, Med. Pediatr. Oncol., 36, 635640, https://doi.org/10.1002/mpo.1141, 2001.

Chin, S. J., Moore, G. A., Zhang, M., Clarke, H. D., Spangehl, M. J., and Young, S. W.: The AAHKS Clinical Research Award: Intraosseous Regional Prophylaxis Provides Higher Tissue Concentrations in High BMI Patients in Total Knee Arthro- plasty: A Randomized Trial, J. Arthroplasty, 33, S13-S18, https://doi.org/10.1016/j.arth.2018.03.013, 2018.

Craig, J., Fuchs, T., Jenks, M., Fleetwood, K., Franz, D., Iff, J., and Raschke, M.: Systematic review and meta-analysis of the additional benefit of local prophylactic antibiotic therapy for infection rates in open tibia fractures treated with intramedullary nailing, Int. Orthop., 38, 1025-1030, https://doi.org/10.1007/s00264-014-2293-2, 2014.

European Committee on Antimicrobail Susceptibility Testing (EUCAST): Antimicrobial wild type distributions of microorganisms, available at: https://mic.eucast.org/ Eucast2/SearchController/search.jsp?action=performSearch\& BeginIndex $=0 \&$ Micdif $=$ mic $\&$ NumberIndex $=50 \&$ Antib $=38 \&$ Specium=-1, last access: 6 May 2019.

Hackett, D. J., Rothenberg, A. C., Chen, A. F., Gutowski, C., Jaekel, D., Tomek, I. M., Parsley, B. S., Ducheyne, P., and Manner, P. A.: The economic significance of orthopaedic infections, J. Am. Acad. Orthop. Surg., 23 Suppl, S1-7, https://doi.org/10.5435/jaaos-d-14-00394, 2015.

Hanberg, P., Bue, M., Obrink-Hansen, K., Kabel, J., Thomassen, M., Tottrup, M., Soballe, K., and Stilling, M.: Simultaneous Retrodialysis by Drug for Cefuroxime Using Meropenem as an Internal Standard-A Microdialysis Validation Study, J. Pharm. Sci., 109, 1373-1379, https://doi.org/10.1016/j.xphs.2019.11.014, 2019.

Harper, K. D., Lambert, B. S., O’Dowd, J., Sullivan, T., and Incavo, S. J.: Clinical outcome evaluation of intraosseous vancomycin in total knee arthroplasty, Arthroplast Today, 6, 220223, https://doi.org/10.1016/j.artd.2020.02.001, 2020.

Jensen, L. K., Koch, J., Henriksen, N. L., Bue, M., Tottrup, M., Hanberg, P., Soballe, K., and Jensen, H. E.: Suppurative Inflammation and Local Tissue Destruction Reduce the Penetration of Cefuroxime to Infected Bone Implant Cavities, J. Comp. Pathol., 157, 308-316, https://doi.org/10.1016/j.jcpa.2017.10.001, 2017.

Joukhadar, C. and Muller, M.: Microdialysis: current applications in clinical pharmacokinetic studies and its potential role in the future, Clinical Pharmacokinetics, 44, 895-913, https://doi.org/10.2165/00003088-200544090-00002, 2005.

Lenguerrand, E., Whitehouse, M. R., Beswick, A. D., Jones, S. A., Porter, M. L., and Blom, A. W.: Revision for prosthetic joint infection following hip arthroplasty: Evidence from the National Joint Registry, Bone Joint Res., 6, 391-398, https://doi.org/10.1302/2046-3758.66.Bjr-2017-0003.R1, 2017.

Loc-Carrillo, C., Wang, C., Canden, A., Burr, M., and Agarwal, J.: Local Intramedullary Delivery of Vancomycin Can Prevent the Development of Long Bone Staphylococcus aureus Infection, PLoS One, 11, e0160187, https://doi.org/10.1371/journal.pone.0160187, 2016.

Mangram, A. J., Horan, T. C., Pearson, M. L., Silver, L. C., and Jarvis, W. R.: Guideline for Prevention of Surgical Site Infection, 1999, Centers for Disease Control and Prevention (CDC) Hospital Infection Control Practices Advisory Committee, Am. J. Infect. Control., 27, 97-132, 1999.

Muller, M.: Science, medicine, and the future: Microdialysis, BMJ Brit. Med. J., 324, 588-591, https://doi.org/10.1136/bmj.324.7337.588, 2002.

Rubio-Martinez, L. M., Lopez-Sanroman, J., Cruz, A. M., Tendillo, F., Rioja, E., and San Roman, F.: Evaluation of safety and pharmacokinetics of vancomycin after intraosseous regional limb 
perfusion and comparison of results with those obtained after intravenous regional limb perfusion in horses, Am. J. Vet. Res., 67, 1701-1707, https://doi.org/10.2460/ajvr.67.10.1701, 2006.

Rybak, M. J.: The pharmacokinetic and pharmacodynamic properties of vancomycin, Clinical infectious diseases, Infectious Diseases Society of America, 42 Suppl 1, S35-39, https://doi.org/10.1086/491712, 2006.

Scheller, D. and Kolb, J.: The internal reference technique in microdialysis: a practical approach to monitoring dialysis efficiency and to calculating tissue concentration from dialysate samples, J. Neurosci. Methods, 40, 31-38, 1991.

Sweet, F. A., Forsthoefel, C. W., Sweet, A. R., and Dahlberg, R. K.: Local Versus Systemic Antibiotics for Surgical Infection Prophylaxis in a Rat Model, The Journal of bone and joint surgery, American volume, 100, e120, https://doi.org/10.2106/JBJS.18.00105, 2018.

Swindle, M. M., Makin, A., Herron, A. J., Clubb Jr., F. J., and Frazier, K. S.: Swine as models in biomedical research and toxicology testing, Vet. Pathol., 49, 344-356, https://doi.org/10.1177/0300985811402846, 2012.

Thomassen, M. B., Hanberg, P., Stilling, M., Petersen, K. K., Soballe, K., Krag, L. B., Hojskov, C. S., and Bue, M.: Local concentrations of gentamicin obtained by microdialysis after a controlled application of a GentaColl sponge in a porcine model, Journal of orthopaedic research, Orthopaedic Research Society, https://doi.org/10.1002/jor.24588, 2020.

Tottrup, M., Soballe, K., Bibby, B. M., Hardlei, T. F., Hansen, P., Fuursted, K., Birke-Sorensen, H., and Bue, M.: Bone, subcutaneous tissue and plasma pharmacokinetics of cefuroxime in total knee replacement patients - a randomized controlled trial comparing continuous and short-term infusion, Acta pathologica, microbiologica, et immunologica Scandinavica, 127, 779788, https://doi.org/10.1111/apm.12996, 2019.
Wahl, P., Guidi, M., Benninger, E., Ronn, K., Gautier, E., Buclin, T., Magnin, J. L., and Livio, F.: The levels of vancomycin in the blood and the wound after the local treatment of bone and soft-tissue infection with antibiotic-loaded calcium sulphate as carrier material, Bone Joint J., 99-b, 1537-1544, https://doi.org/10.1302/0301-620x.99b11.Bjj-20160298.R3, 2017.

Whiteside, L. A.: Prophylactic peri-operative local antibiotic irrigation, Bone Joint J., 98-B, 23-26, https://doi.org/10.1302/0301620X.98B1.36357, 2016.

Xie, L. L., Zhu, J., Yang, M. S., Yang, C. Y., Luo, S. H., Xie, Y., and $\mathrm{Pu}$, D.: Effect of Intra-wound Vancomycin for Spinal Surgery: A Systematic Review and Meta-analysis, Orthop. Surg., 9, 350358, https://doi.org/10.1111/os.12356, 2017.

Young, S. W., Zhang, M., Freeman, J. T., Mutu-Grigg, J., Pavlou, P., and Moore, G. A.: The Mark Coventry Award: Higher tissue concentrations of vancomycin with low-dose intraosseous regional versus systemic prophylaxis in TKA: a randomized trial, Clin. Orthop. Relat. Res., 472, 57-65, https://doi.org/10.1007/s11999013-3038-z, 2014.

Young, S. W., Zhang, M., Moore, G. A., Pitto, R. P., Clarke, H. D., and Spangehl, M. J.: The John N. Insall Award: Higher Tissue Concentrations of Vancomycin Achieved With Intraosseous Regional Prophylaxis in Revision TKA: A Randomized Controlled Trial, Clin. Orthop. Relat. Res., 476, 66-74, https://doi.org/10.1007/s11999.0000000000000013, 2018.

Zmistowski, B., Karam, J. A., Durinka, J. B., Casper, D. S., and Parvizi, J.: Periprosthetic joint infection increases the risk of one-year mortality, J. Bone Joint. Surg. Am., 95, 2177-2184, https://doi.org/10.2106/jbjs.1.00789, 2013. 